\title{
Solid State Mobile Lidar for Ozone Atmospheric Profiling
}

\author{
Russell De Young \\ Science Directorate, MS401A, NASA Langley Research Center, Hampton, VA 23681 \\ Russell.j.deyoung@nasa.gov \\ William Carrion \\ Coherent Applications Inc., Hampton, VA 23681 \\ Denis Pliutau and Rene Ganoe \\ Science Systems and Applications Inc. Hampton, VA 23681
}

\begin{abstract}
A tunable Ce:LiCAF laser is pumped by a CLBO crystal pumped by a doubled Nd:YLF laser running at $1 \mathrm{kHz}$. The UV tunable Ce:LiCAF laser produces two UV pulses between 280 to $295 \mathrm{~nm}$. These pulses are transmitted into the atmosphere to profile the concentration of ozone as a function of altitude.

OCIS codes: (010.0010) Atmospheric and Ocean Optics; (010.0280) Remote sensing and sensors
\end{abstract}

\section{Introduction}

A compact differential absorption lidar (DIAL) system has been developed at NASA Langley Research Center to provide ozone, aerosol and cloud atmospheric measurements in a mobile trailer for ground-based atmospheric ozone campaigns. Since ozone is a pollutant in the lower atmosphere, it is important to understand its generation and transport for air-quality pollution monitoring and mitigation. This lidar will be integrated into the Air Quality lidar Network (AQLNet) currently made up of four other ozone lidars across the country.

\section{Lidar Configuration}

The lidar system consists of a UV and green laser transmitter, a telescope and an optical signal receiver box with associated (Licel) photon counting and analog channels as show in Fig. 1. The laser transmitter consist of a Coherent Evolution 30 TEM00 1-kHz diode pumped Q-switched Nd:YLF inter-cavity doubled laser pumping a Ce:LiCAF tunable UV laser with all the associated power and lidar control support units on a single system rack[1]. A customdesigned Ce:LiCAF tunable UV laser has a wavelength range of 280 to $295-\mathrm{nm}$ that is selectable between two or more wavelengths as shown in Fig. 2. The current wavelengths are online $286.4 \mathrm{~nm}$ and offline $293.1 \mathrm{~nm}$. The 527$\mathrm{nm}$ visible beam is transmitted into the atmosphere for aerosol measurements. The CLBO fourth harmonic $262 \mathrm{~nm}$ pump beam is split by a beamsplitter into two pump beams that pump each face of the Ce:LiCAF crystal. A short laser cavity consisting of a $60 \%$ reflective ( $1 \mathrm{~m}$ radius of curvature) output mirror, a dispersive prism and a flat $\mathrm{HR}$ mirror is used to produce the UV wavelengths. In order to produce different wavelengths, the high-reflectivity flat rear mirror is mounted on a servo controlled galvanometer motor to allow rapid tuning between the on and offline ozone wavelengths. Typical laser results are $6.8-\mathrm{W}$ at $527-\mathrm{nm}, 800-\mathrm{mW}$ at $262-\mathrm{nm}$ and $130-\mathrm{mW}$ at the UV transmitted wavelengths. The lidar receiver system consists of a receiver telescope with a 40-cm diameter parabolic mirror. A fiber optic cable transmits the received signal from the telescope to the receiver box, which houses the detectors. A separate telescope with PMT and filter is used to sample the very near field to allow ozone profiles from 100-m above ground.

To obtain an ozone atmospheric measurement, the transmitter sends a laser pulse into the atmosphere at alternating on-line and off-line wavelengths $(500 \mathrm{~Hz}$ each line)[2]. The $527-\mathrm{nm}$ green laser output is always transmitted giving a return from atmospheric aerosols. The system has been configured to enable mobile operation from a trailer which is environmentally controlled, and is towed with a truck to sites that are equipped with power. The objective is to make the system mobile such that it can be setup at remote sites to support major air quality field campaigns.

\section{Ozone Lidar Results}

Figure 3 is an example of an ozone curtain atmospheric plot in the Hampton, VA on September 24, 2013 starting at 7:52 AM local time showing the concentration of atmospheric ozone in parts per billion volume as a function of altitude. The ozone concentration is color coded. In the example the ozone concentration is shown from 600-m to 
3000-m. The ozone above the boundary layer at about 1500-m is probably transported from Northern Virginia from back trajectory analysis. Below the boundary layer, ozone in generated locally from cars and industrial processes. During the day sunlight increases the atmospheric temperature resulting in increased ozone in the boundary layer. This lidar system demonstrates the ability to deploy small mobile ozone lidars for remote sensing measurements at any location.

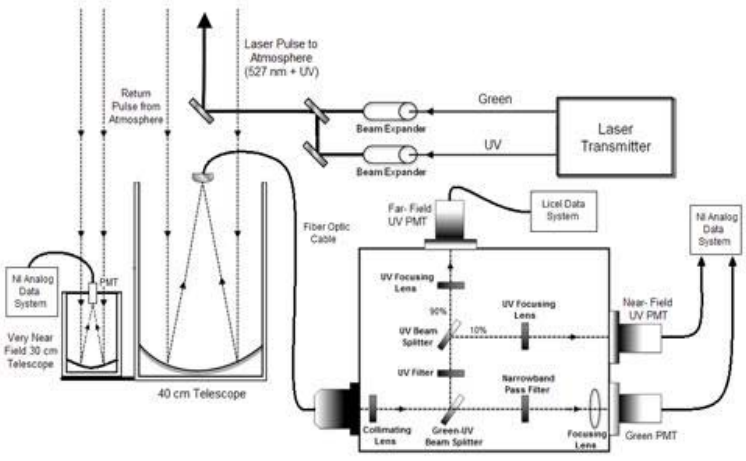

Fig. 1 Overall ozone lidar schematic.

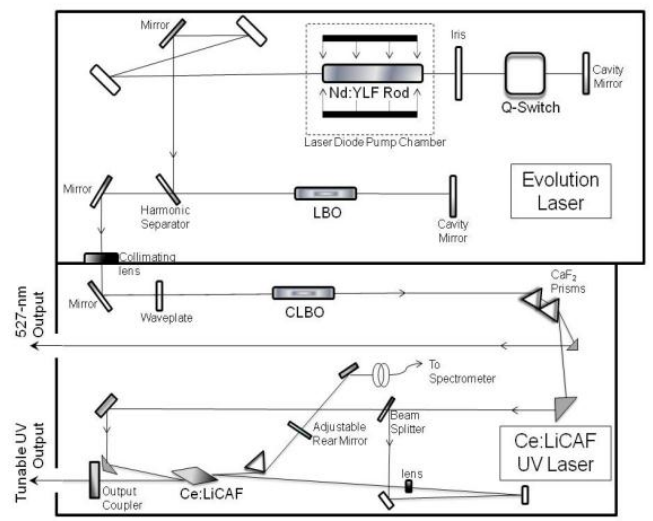

Fig.2 Laser transmitter schematic.

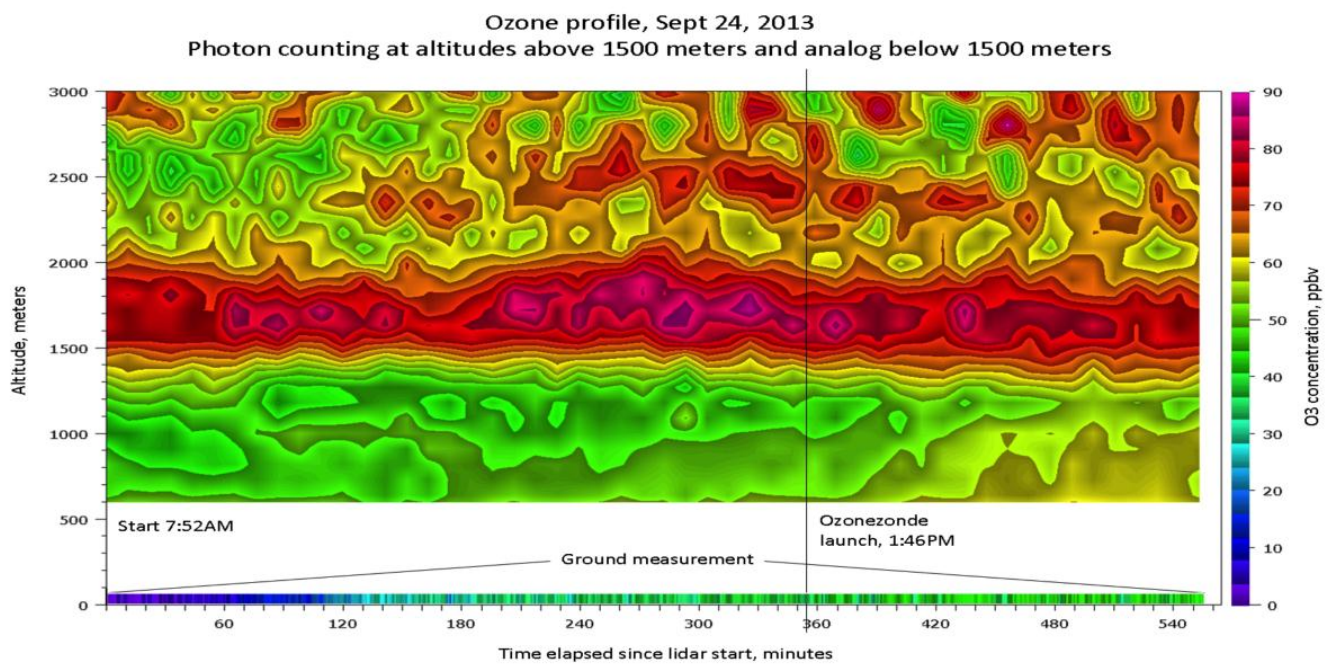

Fig. 3 Example of curtain plot of ozone showing ozone transport from Northern Virginia above the boundary layer and local ozone generation below the boundary layer.

\section{References}

[1] Fromzel, V.A., Prasad, C.R., Petrosyan, K.B., Liaw, Y., Yakshin, M.A., Shi, W. and De Young, R.J.: Tunable, Narrow Linewidth, High Repetition Frequency Ce:LiCAF Lasers Pumped by the Fourth Harmonic of a Diode-Pumped Nd:YLF Laser for Ozone DIAL Measurements. Advances in Optical and Photonics Devices, Ed. Ki Young Kim, ISBN 978-953-7619-76-3, Intech, January 2010.

[2]. Denis Pliutau, Russell DeYoung, “UV Lidar Receiver Analysis for Tropospheric Sensing of Ozone,” NASA/TM-2013-218038, 2013. 